RESEARCH ARTICLE

\title{
Application of un-fertilized ovary culture to identify elite mother palms of Cocos nucifera L. with regenerative potential ${ }^{\dagger}$
}

\author{
V.R.M. Vidhanaarachchi ${ }^{1 *}$, S.C. Fernando ${ }^{2}$, P.I.P. Perera ${ }^{1}$ and L.K. Weerakoon ${ }^{1}$ \\ ${ }^{1}$ Tissue Culture Division, Coconut Research Institute, Bandirippuwa Estate, Lunuwila. \\ ${ }^{2}$ School of Botany, University of Melbourne, Victoria 3010, Australia.
}

Revised: 22 November 2012 ; Accepted: 20 December 2012

\begin{abstract}
Un-fertilized ovary is a promising explant for micropropagation of coconut. However, due to high heterozygocity in coconut, in vitro performance varies greatly among palms. In this study, callogenesis, somatic embryogenesis and plant regeneration potential of 35 Sri Lanka Tall (SLT) and 20 Dwarf x Tall hybrid (DxT) elite palms were assessed to select suitable mother palms for clonal propagation. Callusing was induced from ovaries excised from immature female flowers, cultured on CRI 72 basal medium containing $100 \mu \mathrm{M}$ of 2,4 dichlorophenoxy acetic acid (2,4-D), $9 \mu \mathrm{M}$ of thidiazuron and activated charcoal at $0.1 \%$. The induced calli were proliferated in two cycles. Somatic embryos were induced in low 2,4-D $(66 \mu \mathrm{M})$ medium and matured in hormone-free medium with a consecutive transfer to a medium with $20 \mu \mathrm{M}$ of 2 -isopentyladenine. Germination of somatic embryos and the development of shoots occurred in $\mathrm{Y}_{3}$ medium with $0.45 \mu \mathrm{M}$ of gibberellic acid. Ovaries of SLT and DxT palms initiated callusing by 74.0 and $65.0 \%$, respectively. Percentage of explants that developed callus varied from 4 to $50 \%$ in SLT and 9 to $57 \%$ in DxT. Calli of DxT did not grow further to regenerate somatic embryos. However, SLT calli proliferated in two cycles and regenerated a mean of 12.5 well-developed embryogenic structures per ovary. The maximum welldeveloped embryogenic structures obtained were 70 in few ovaries. Twelve out of 35 SLT palms regenerated shoots with the number of shoots per inflorescence ranging from 1 to 205 . The results showed that not only individual palms but also individual explants respond differently to in vitro culture. The study enabled identification of 12 SLT palms as responsive to in vitro culture.
\end{abstract}

Keywords: Coconut, mother palm selection, somatic embryogenesis, un-fertilized ovary culture.

\section{INTRODUCTION}

Coconut (Cocos nucifera L.), an important palm in the tropics, needs improvement especially in coconut producing countries like Sri Lanka. Tissue culture techniques are now used to speed-up crop improvement by cloning of elite planting material. Since 1970 's, in vitro cloning of coconut has been attempted using various tissues such as root (Justin, 1978), shoot tip (Weerakoon, 2004), immature inflorescence (Branton \& Blake, 1986; Verdeil et al., 1994), tender leaf (Pannetier \& BuffardMorel, 1982), immature zygotic embryo (Karunaratne \& Periyapperuma, 1989; Fernando \& Gamage, 2000) and plumule (Hornung, 1995a; Chan et al., 1998; Fernando et al., 2003). Although several preliminary protocols have been developed, their efficiencies have been limited to regeneration of a few clonal plants.

The high potential of the un-fertilized ovary explants for cloning of coconut was reported recently (Perera et al., 2007). Plant regeneration from tissues in the un-fertilized ovary occurs through indirect somatic embryogenesis as reported for all other explants of coconut (Karunaratne \& Periyapperuma, 1989; Fernando, 2001). This explant of Sri Lanka Tall palms gave a callusing frequency of $76 \%$ and a plant regeneration frequency of $70 \%$ (Perera et al., 2009). The study has reported that un-fertilized ovary is the most suitable explant for cloning coconut due to its somatic nature and high regeneration potential (Perera et al., 2009). Immature inflorescences bearing un-fertilized ovaries can be excised from the palm with minimal damage to the palm.

\footnotetext{
"Corresponding author (vijitharma@yahoo.com)

${ }^{\dagger}$ The paper is based on the poster presentation made at the $3^{\text {rd }}$ Symposium on Plantation Crop Research, $30^{\text {th }}$ September- $1^{\text {st }}$ October 2010, Colombo.
} 
Generally, the potential for in vitro regeneration shows strong genotype dependence in many plant species (Tomas \& Smith, 1985; Cheliak \& Klimazenska, 1995; Zhang \& Yakahata, 2001) and past experience shows that coconut is not an exception (Fernando, 2001; Weerakoon, 2008). Due to the high heterozygocity, each coconut palm can be considered as an individual genotype. Thus, identification of mother individual palms responsive to in vitro culture would lead to efficient cloning of elite palms. Identification of such palms is only possible by studying responses of ovary explants collected from a large number of elite mother palms. Therefore, this study was undertaken with the objective of applying the protocol developed by Perera et al. (2009), in identifying palms with high amenability to clonal propagation among elite mother palms of two commercially important cultivars [Sri Lanka Tall (SLT) and Dwarf x Tall hybrid (DxT)] (Vidhanaarachchi et al., 2010) .

\section{METHODS AND MATERIALS}

\section{Experimental material}

Thirty five SLT (25-year old) and 20 DxT (40-year old) high yielding mother palms showing a vigorous growth were selected for the study. The age difference between palms of the two cultivars could not be avoided due to limited availability of palms. The youngest open inflorescence in a palm was considered to be at maturity stage 0 and the inflorescence that will open after four months was considered to be at maturity stage -4 . Female flowers were collected from immature inflorescences at -4 maturity stage (Perera et al., 2009).

\section{Un-fertilized ovary culture}

Female flowers were disinfected in $2 \%(\mathrm{v} / \mathrm{v})$ Clorox for $12 \mathrm{~min}$ and rinsed 5 times with sterile distilled water. The ovaries were dissected under stereo binocular microscope and the crushed explants were placed on callus induction medium, which consisted of basal CRI 72 (Karunaratne \& Periyapperuma, 1989), supplemented with $100 \mu \mathrm{M}$ 2,4 -dichlorophenoxy acetic acid (2,4-D) and $9 \mu \mathrm{M}$ thidiazuron (TDZ) for 10 wks (Perera et al., 2009). The number of ovaries that could be collected per palm varied from 6 to 71. Initial calli were further proliferated by dissection of embryogenic structures under stereo binocular microscope and subculturing into fresh callus induction medium (without TDZ). After 8 wks, the embryogenic structures that developed on callus (of first cycle) were separated and subcultured (in the same medium) for the second cycle.
After the 2 cycles, calli were transferred to regeneration medium as described by Perera et al. (2009), which was modified by increasing 2-isopentyladenine (2iP) from $5 \mu \mathrm{M}$ to $20 \mu \mathrm{M}$ and omitting 6-benzylaminopurine (BAP). Well-developed embryogenic structures were individually transferred to CRI 72 medium supplemented with $66 \mu \mathrm{M} 2,4-\mathrm{D}$ and incubated for $4-6$ wks. They were transferred to the same basal medium without plant growth regulators for 4 wks and to the basal medium supplemented with $20 \mu \mathrm{M} 2 \mathrm{iP}$ for 4 wks. Subsequently, somatic embryos were maintained in $\mathrm{Y}_{3}$ medium (Eeuwens, 1976) supplemented with $0.45 \mu \mathrm{M}$ gibberellic acid $\left(\mathrm{GA}_{3}\right)$ by subculturing on to fresh media at $6 \mathrm{wk}$ intervals until they were germinated and shoots were well-developed.

All culture media were supplemented with $0.1 \%$ $(\mathrm{w} / \mathrm{v})$ activated charcoal (BDH 33033) and the cultures were maintained at $28 \pm 1{ }^{\circ} \mathrm{C}$ in the dark until somatic embryos converted into shoots. The shoots were maintained at $28{ }^{\circ} \mathrm{C}$ under $16 \mathrm{~h}$ photoperiod (PAR: 25 $\left.\mu \mathrm{mol} \mathrm{m} \mathrm{m}^{-2} \mathrm{~s}^{-1}\right)$.

\section{Data collection and analysis}

From all the initiated cultures, the number of ovary explants that initiated callus and the number of explants that produced embryogenic callus were recorded after 10 wks of incubation. Number of embryogenic structures that developed into callus after the first cycle of callus proliferation, number of well-developed embryogenic structures that were transferred to regeneration medium after the second cycle of callus proliferation and number of shoots regenerated per palm were recorded. The following calculations were done for each palm to identify the most responsive individuals.

Callusing frequency $(\%)=$ number of ovaries producing callus/total number of ovary explants cultured x 100

Mean number of embryogenic callus per ovary (cycle 1) $=$ total number of embryogenic structures developed into callus/number of ovaries producing embryogenic callus

Mean number of well-developed embryogenic structures per ovary $($ cycle 2$)=$ total number of well-developed embryogenic structures transferred to regeneration medium/ number of ovaries producing embryogenic callus 


\section{Statistical analysis}

The variation in callusing frequency and the mean number of embryogenic callus per ovary (cycle 1 ) between the 2 cultivars was compared using the t-test.

\section{RESULTS AND DISCUSSION}

\section{Callogenesis}

The crushed explants enlarged after one week in culture. The signs of callusing were visible to the naked eye only after four weeks. After ten weeks, translucent calli appeared on some explants while the others became enlarged or turned necrotic. Ovaries from $74 \%$ palms of SLT and $65 \%$ palms of DxT produced calli. The callusing frequency per palm varied from 3.6 to $50.0 \%$ and from 8.6 to $57.1 \%$ with a mean of 13.8 and $19.0 \%$ in ovary explants of SLT and DxT palms, respectively. The mean callusing frequency between the two cultivars was statistically not significant (Table 1).
The embryogenic potential of an explant may be affected by several factors like the genotype, environmental conditions of mother palm, mother plant maturity, explant maturity etc., even under optimal culture conditions (Hornung, 1995b ; Fernando, 2001). In the present study, the length of -4 inflorescences collected from SLT and DxT palms varied from 40 to $55 \mathrm{~cm}$. The number of female flowers per inflorescence also varied (6 - 71). Dissected ovaries were approximately $1-3 \mathrm{~mm}$ in diameter and showed a gradient in development even within the same inflorescence.

These variations could also affect the uniformity of ovary explants resulting in differential responses to culture conditions applied in this study. Genotypic effects may also play a role in palm to palm variation in callusing frequency within a cultivar. These results are comparable to the results reported for immature inflorescence explants of coconut that showed a variation of $0-30 \%$ callusing (Vidhanaarachchi \& Weerakoon, 1997) and oil palm leaf explants that showed 5-61\% callusing (Wooi, $1995)$ in explants collected from different mother palms.

Table 1: In vitro response of unfertilized-ovaries collected from two different cultivars of coconut

\begin{tabular}{|c|c|c|c|c|c|c|}
\hline Cultivar & $\begin{array}{l}\text { No. of mother } \\
\text { palms tested }\end{array}$ & $\begin{array}{l}\text { Palms producing } \\
\text { callus }(\%)\end{array}$ & $\begin{array}{l}\text { Mean callusing } \\
\text { frequency per } \\
\text { palm }(\%)\end{array}$ & $\begin{array}{c}\text { Palms producing } \\
\text { embryogenic } \\
\text { callus }(\%)\end{array}$ & $\begin{array}{l}\text { Mean number } \\
\text { of embryogenic } \\
\text { callus per ovary } \\
\quad(\text { cycle } 1)^{\mathrm{a}}\end{array}$ & $\begin{array}{c}\text { Mean number of } \\
\text { well-developed } \\
\text { embryogenic } \\
\text { structures per } \\
\text { ovary (cycle 2) a }\end{array}$ \\
\hline Sri Lanka Tall & 35 & 74.0 & $\begin{array}{c}13.8 \\
(3.6-50.0)\end{array}$ & 54.0 & $\begin{array}{c}2.8 \\
(0.5-7.8)\end{array}$ & $\begin{array}{c}12.5 \\
(0.5-48.5)\end{array}$ \\
\hline Dwarf x Tall & 20 & 65.0 & $\begin{array}{c}19.0 \\
(8.6-57.1)\end{array}$ & 45.0 & $\begin{array}{c}0.6 \\
(0.4-1.6)\end{array}$ & 0.0 \\
\hline Significance & & & NS & & $*$ & \\
\hline
\end{tabular}

Variation in response is given in parentheses; ${ }^{a}=$ Values were calculated based on palms producing embryogenic callus only; NS = not significant; * = significant

Callus that developed from different ovaries also showed a variation in size and morphology. Ovaryderived calli of the cultivar DxT were smaller, developed fewer embryogenic structures and were more compact and less translucent when compared to that of SLT (Table 1).

\section{Callus proliferation}

Generally, coconut explants produce highly compact calli in small quantities. Previous attempts to increase the quantity of coconut calli were unsuccessful as cell suspensions could not be established due to the compact nature of the callus. Even though crushed callus developed into embryogenic callus, it did not show a fast growth (Fernando, 2001). Perez et al. (2006) introduced an efficient method in which selected embryogenic callus and somatic embryos induced from plumules could be repeatedly subcultured to achieve a large number of somatic embryos as high as 100,000 per explant. Perera et al. (2009) was able to increase the growth of coconut ovary-derived callus by the application of this method. However, the maximum number of embryogenic callus clumps possible was 25 per original ovary callus and this depended on the quality and the size of the original callus induced from these explants. 
In the present study, ovaries of 54 and $45 \%$ SLT and DxT palms, respectively produced translucent nodular calli with embryogenic structures (Figure 1a), which were suitable for somatic embryo regeneration. In general, calli from DxT explants were smaller in size compared to those of SLT explants. Thus, the number of embryogenic structures obtained per initial callus was significantly higher in SLT (5.4) than in DxT (3.4). In the first cycle, embryogenic structures derived from DxT ovaries did not grow satisfactorily and developed a mean of 0.6 embryogenic calli per ovary, whereas those developed from SLT proliferated well and showed a mean of 2.8 embryogenic calli per ovary. At the end of the second cycle, a mean of 12.5 well-developed embryogenic
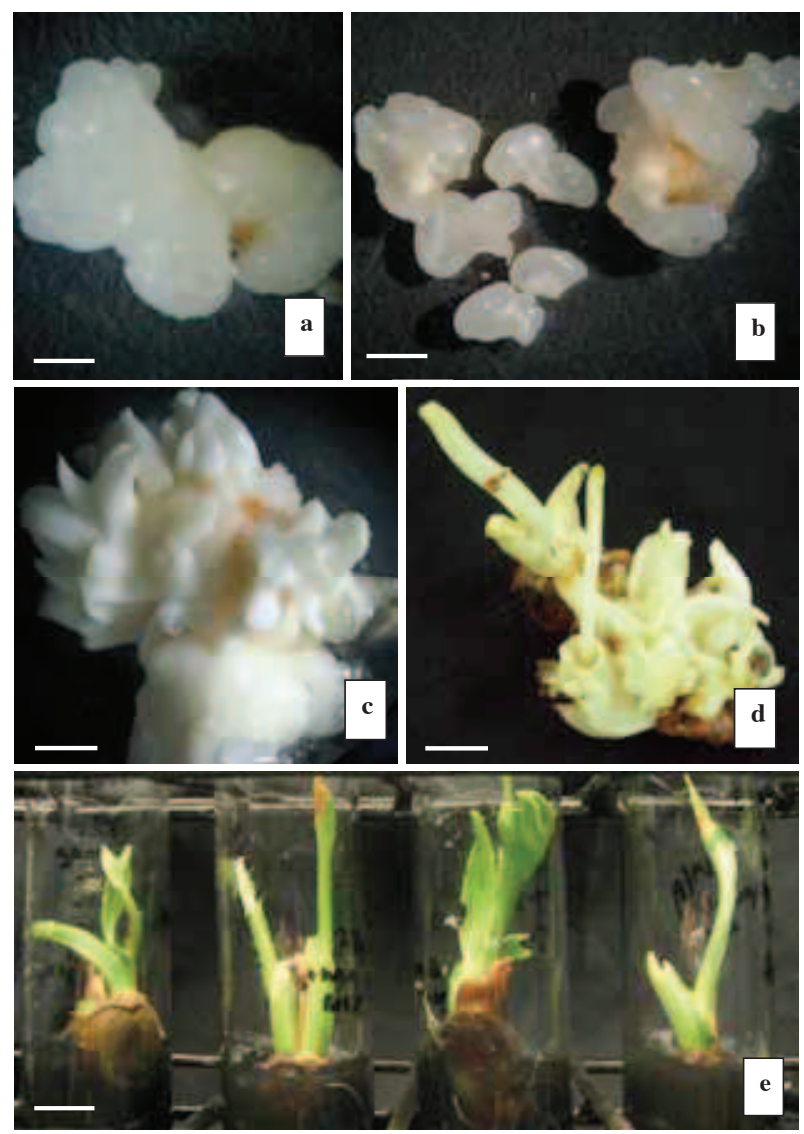

Figure 1: Plant regeneration from ovary-derived callus of coconut (Cocos nucifera L.). a. Embryogenic callus developed on explant after 10 weeks of culture (bar $=33 \mathrm{~mm})$. b. Well developed embryogenic structures ready to be transferred to somatic embryogenesis medium (bar $=33 \mathrm{~mm}$ ). c. Somatic embryos $(\mathrm{bar}=50 \mathrm{~mm})$. d. Shoot regeneration (bar $=1 \mathrm{~cm})$. e. Plantlets regenerated from ovary-derived callus $($ bar $=1 \mathrm{~cm})$. structures per ovary per SLT palm regenerated and could be transferred to regeneration medium (Figure 1b). In a few individual ovaries, highly convoluted, translucent fast-growing callus developed and they regenerated a large number of well-developed embryogenic structures. The highest number of well-developed embryogenic structures obtained per ovary explant (at the end of the second cycle) was 70 .

The results clearly showed a difference in the ability among ovary explants to develop fast-growing callus that could regenerate somatic embryos, which may be due to genotypic effect or differences in stage of maturity of ovaries.

\section{Somatic embryogenesis and plant regeneration}

As in other plant species, the endogenous auxin concentration is one of the determining factors for the induction of somatic embryogenesis in coconut (Blake, 1990). Gradual reduction in auxin concentration with a corresponding increase in cytokinin level permits initiation and further development of somatic embryos.

Initially, ovary explants were subjected to a very high level $(100 \mu \mathrm{M})$ of $2,4-\mathrm{D}$ in the medium. On transferring well-developed translucent embryogenic structures to the low $(66 \mu \mathrm{M})$ 2,4-D medium, nodular structures regenerated in the periphery. When these were transferred to hormone free medium, the nodular structures enlarged and turned opaque. Once they were transferred to the high cytokinin $(20 \mu \mathrm{M} 2 \mathrm{iP})$ medium, they became globular and somatic embryos developed (Figure 1c). Embryo maturation culminated with the formation of elongated somatic embryos. These mature somatic embryos germinated when transferred to $\mathrm{Y}_{3}$ medium (Eeuwens, 1976) with $\mathrm{GA}_{3}$. By maintaining them in the same medium, healthy shoots developed (Figures 1d \& e).

Ovaries of $34 \%$ of SLT palms under the study (12 palms) finally developed shoots, but the ovaries of DxT palms did not develop callus from which shoots could be recovered. The number of shoots regenerated per inflorescence in SLT palms varied from 1 to 205 showing the highly variable response of individual palms (Table 2). The shoot regeneration potential of several palms was higher than that was achieved by Perera et al. (2009). This again may be due to the genotypic differences of palms used in the two studies. Further, use of a higher cytokinin level and an increased callus production due to two cycles of callus proliferation before regeneration also may have affected higher somatic embryo regeneration. 
Table 2: Variation in shoot regeneration potential of SLT palms

\begin{tabular}{cccc}
\hline $\begin{array}{c}\text { SLT mother } \\
\text { palm regenerated } \\
\text { shoots (out of } \\
\text { the 35 tested) }\end{array}$ & $\begin{array}{c}\text { Number of } \\
\text { ovaries } \\
\text { cultured }\end{array}$ & $\begin{array}{c}\text { Number of } \\
\text { ovaries } \\
\text { developed } \\
\text { callus }\end{array}$ & $\begin{array}{c}\text { Total number } \\
\text { of shoots } \\
\text { regenerated }\end{array}$ \\
\hline 1 & 17 & 7 & 205 \\
2 & 27 & 12 & 24 \\
3 & 19 & 7 & 19 \\
4 & 19 & 7 & 7 \\
5 & 35 & 3 & 1 \\
6 & 24 & 1 & 16 \\
7 & 15 & 1 & 3 \\
8 & 25 & 4 & 1 \\
9 & 14 & 2 & 1 \\
10 & 16 & 2 & 5 \\
11 & 28 & 3 & 6 \\
12 & 10 & 3 & 3 \\
\hline
\end{tabular}

Among-palm variation is reported in oil palm, where depending on the cultivar, $23-70 \%$ of the explanted palms responded to regeneration at variable frequencies (Rajanaidu et al., 1997). Somatic embryogenesis is shown to be the stage under the strongest genetic control in clonal propagation of white spruce (Park et al., 1994), loblolly pine (Pullman \& Johnson, 2002) and maize (Tomas \& Smith, 1985). Apart from the influence of genetic factors, explant quality, environmental conditions under which the mother plant developed also affect in vitro performance (Hernandez-Fernandez \& Christie, 1989; Basra, 1995).

It is also worth reporting that a higher number of shoots per inflorescence were regenerated from ovaries producing highly convoluted, fast-growing callus showing higher proliferation. Such callus proliferation might be a collective effect of genotype of the individual palm and optimum maturity stage of the ovary.

When compared to the performance of SLT palms, the poor performance of DxT may be due to the use of older mother palms or the use of culture conditions previously developed for SLT ovary culture.

\section{CONCLUSION}

This study confirmed that un-fertilized ovaries are a good source of explants for clonal propagation of elite coconut palms. Initial callus derived from ovaries of SLT palms could be successfully proliferated in two cycles to increase the quantity. A variable response of genotypes to the tested protocol was noted. The genotypic influence on palm response at the stage of callus proliferation and plant regeneration could be observed. The SLT palms were more amenable to clonal propagation using the tested protocol. As a result of the present study, twelve high-yielding SLT palms with in vitro regeneration potential could be identified. Under the present culture conditions, cultivar DxT did not perform well. Therefore, optimum culture conditions for DxT have to be identified.

\section{Acknowledgement}

Authors gratefully acknowledge the assistance of Mr. Nalin Kumara and Mr. Kapila Prasanna in inflorescence collection. Authors are also thankful to Mrs. P. Waidyaratne, for statistical analysis and the staff, Tissue Culture Division, Coconut Research Institute for the support extended in various ways.

\section{REFERENCES}

1. Basra A.S.(1995). Seed quality: Basic Mechanism and Agriculture Implications, pp. 389. Haworth Press, New York, USA.

2. Blake J. (1990). Coconut (Cocos nucifera L.): Micropropagation. Biotechnology in Agriculture and Forestry, vol. 10, Legumes and Oil Seeds Crops I (ed. Y.P.S. Bajaj), pp. 538 - 554. Springer-Verlag, Berlin, Germany.

3. Branton R.L. \& Blake J. (1986). Clonal propagation of coconut palm. Cocoa and Coconut: Progress and Outlook (ed. E. Pushparajah), pp. 771 - 780. Incorporated Society of Planters, Kuala Lumpur, Malayasia.

4. Chan J.L., Saenz 1., Talavera C., Hornung R., Robert M. \& Oropeza C. (1998). Regeneration of coconut (Cocos nucifera L.) from plumule explants through somatic embryogenesis. Plant Cell Report 17: 515 - 521.

5. Cheliak W.M. \& Klimazenska K. (1995). Genetic variation in somatic embryogenic response in open-pollinated families of black spruce. Theoretical and Applied Genetics 82: $185-190$.

6. Eeuwens C.J. (1976). Mineral requirements for growth and callus initiation of tissue explants excised from mature coconut palms (Cocos nucifera L.) and cultured in vitro. Physiologia Plantarum 36: 23 - 28.

7. Fernando S.C. (2001). Studies on somatic embryogenesis of coconut (Cocos nucifera L.). PhD thesis, University of Colombo, Colombo.

8. Fernando S.C. \& Gamage C.K.A. (2000). Abscisic acid induced somatic embryogenesis in immature embryo explants of coconut (Cocos nucifera L.). Plant Science 151: $193-198$.

9. Fernando S.C., Verdeil J.L., Hocher V., Weerakoon L.K. \& Hirimburegama K. (2003). Histological analysis of plant regeneration from plumule explants of coconut (Cocos nucifera L.). Plant Cell Tissue and Organ Culture 72: $281-284$. 
10. Hernandez-Fernandez M.M. \& Christie B.R. (1989). nheritance of somatic embryogenesis in alfalfa (Medicago sativa L.). Genome 32: 318 - 321.

11. Hornung R. (1995a). Micropropagation of Cocos nucifera L. from plumular tissues excised from mature zygotic embryos. Plantations Recherche Developpment 212: $38-41$.

12. Hornung R. (1995b). Initiation of callogenesis in coconut palm (Cocos nucifera L.), Lethal Yellowing: Research and Practical Aspects (eds. C. Oropeza, F.W. Howard \& G.R. Ashburner), pp. 203 - 215. Kluwer Academic Publishers, Dordrecht, Germany.

13. Justin S.H.F.W. (1978). Vegetative propagation of coconuts. Report of East Malling Research Station, pp. 175 - 176.

14. Karunaratne S. \& Periyapperuma K. (1989). Culture of immature embryos of coconut, Cocos nucifera L.: callus proliferation and somatic embryogenesis. Plant Science 62: $247-253$.

15. Pannetier C. \& Buffard-Morel J. (1982). Premiers resultats concernant la production d'embryons somatiques a partir de tissus foliaires de cocotier, Cocos nucifera. Oleagineux 37: $349-354$.

16. Park Y.S., Pond S.E. \& Bonga J.M. (1994). Genetic control in somatic embryos exposed to storage, maturation treatments, germination and cryopreservation. Theoretical and Applied Genetics 89: 742 - 750.

17. Perera P.I.P., Hocher V., Verdeil J., Doulbeau S., Yakandawala D.M.D. \& Weerakoon L.K. ( 2007). Unfertilized ovary: a novel explant for coconut (Cocos nucifera L.) somatic embryogenesis. Plant Cell Report 26: $1-8$.

18. Perera P.I.P., Vidhanaarachchi V.R.M., Gunathilake T.R., Yakandawala D.M.D., Hocher V., Verdeil J. \& Weerakoon L.K. (2009). Effect of plant growth regulators on ovary culture of coconut (Cocos nucifera L.). Plant Cell Tissue and Organ Culture 99: $73-81$.

19. Perez-Nunez M.T., Chan J.L., Saenz L., Gonzales T., Verdeil J.L. \& Oropeza C. (2006). Improved somatic embryogenesis from coconut (Cocos nucifera L.) plumule explants cultured in vitro. In Vitro Cellular and
Development Biology of Plants 42: 37 - 43.

20. Pullman G.S. \& Johnson S. (2002). Somatic embryogenesis in loblolly pine (Pinus taeda L.): improving culture initiation rates. Annals of Forest Science 59: $663-668$.

21. Rajanaidu N., Rohani O. \& Jalani B.S. (1997). Oil palm clones: current status and prospects for commercial production. The Planter 73: $163-184$.

22. Tomas D.T. \& Smith O.S. (1985). The effect of parental genotype on initiation of embryogenic callus from elite maize (Zea mays L.) germplasm. Theoretical and Applied Genetics 70: $505-509$.

23. Verdeil J.L., Huet C., Grosdemange F. \& Buffard-Morel J. (1994). Plant regeneration from cultured immature inflorescences of coconut (Cocos nucifera L.): evidence for somatic embryogenesis. Plant Cell Report 13: 218 - 221.

24. Vidhanaarachchi V.R.M., Fernando S.C., Perera P.I.P. \& Weerakoon L.K. (2010). Identification of coconut mother palms with in vitro regeneration potential using unfertilized ovary culture. Proceedings of the $3^{\text {rd }}$ Symposium on Plantation Crop Research, $30^{\text {th }}$ September- $1^{\text {st }}$ October, Sri Lanka, pp. 333.

25. Vidhanaarachchi V.R.M. \& Weerakoon L.K. (1997). Callus induction and direct shoot formation in in vitrocultured immature inflorescence tissues of coconut. Cocos 12: $39-43$.

26. Weerakoon L.K. (2004). Coconut tissue and embryo culture in Sri Lanka: current developments and future challenges. Proceedings of the International Conference of the Coconut Research Institute of Sri Lanka, 8-11 September, Colombo. pp. $41-61$.

27. Weerakoon L.K. (2008). Annual Report. Coconut Research Institute, Bandirippuwa Estate, Lunuwila.

28. Wooi K.C. (1995). Oil palm tissue culture-current practice and constraints. Proceedings of the ISOPB International Symposium on Recent Development in Oil Palm Tissue Culture and Biotechnology, 1993, Kuala Lumpur, Malaysia. pp. $21-32$.

29. Zhang F.L. \& Yakahata Y. (2001). Inheritance of microspore embryogenic ability in Brassica crops. Theoretical and Applied Genetics 103: 254 - 258. 